\title{
HEAT STRESS IN YOUNG ADULTS ${ }^{\dagger}$
}

\author{
R. VAN ZYL SMIT, M.B. B.Ch (Witwatersrand) F.C.P. (SA) M.R.C.P. (UK).*
}

\section{SUMMARY}

The physiology of heat regulation is briefly discussed. Heat exhaustion and heat stroke are described and finally heat stroke as a medical emergency is dealt with.
Man has little difficulty in combatting cold (huddling together, shivering, exercise, better insulation, clothes, etc.) - escape from heat unfortunately is not so easy. The only physiological devices available for cooling are sweating, panting and vaso-dilatation.

The core temperature of the human body reflects the balance between heat production and heat loss.

In temperate climates:

$50 \%$ of heat produced is lost through radiation

$25 \%$ by convection in cool air

$25 \%$ by evaporation of insensible perspiration

With increased heat production virtually all the extra heat has to be got rid of by evaporation, i.e. sweating. The skin temperature rises very little and it may even cool down due to evaporation from its surface, further reducing the temperature gradient from skin to air.

As the ambient temperature approaches $35,5^{\circ} \mathrm{C}$, all heat produced by the body must be lost by sweating. At higher temperatures, the body gains heat from the environment

*Head: Renal Unit, Groote Schuur Hospital.

$\lceil$ Paper read at the Bloemfontein Congress June 1983.

\section{OPSOMMING}

Die fisiologie van hitte regulasie word kortliks bespreek. Hitte-uitputting en hitteslag word beskryf en ten slotte word hitteslag as 'n mediese noodtoestand behandel.

which places an even greater burden on the sweating mechanism.

\section{Sweating}

The rate of heat loss from sweating depends largely on two factors. The most important is the relative humidity, far greater cooling being produced in dry air. Secondly, evaporation aided by air currents which is maximized by wearing loose-fitting clothing allowing good ventilation, aids heat loss.

It has been shown that sweating may begin as soon as 1,5 seconds after commencing heavy exercise; it reaches an equilibrium after 30 minutes, and thereafter is in direct relation to workload (heat production). At maximum rates of work, up to $3,5 \mathrm{l} /$ hour of sweat may be lost, each 1 litre of which, if totally evaporated on the skin surface, would cool by $580 \mathrm{~K} / \mathrm{cal}$. All sweat which drips off the body is, of course, lost for cooling purposes.

\section{Heat gain}

Heat gained from a hot environment is generally selfevident. What is less well appreciated is the tremendous heat produced from muscular activity.
Metabolic rate

Muscular activity

SDA effect

Environment
Radiation

Conduction

Convection

Evaporation
HEAT

GAIN

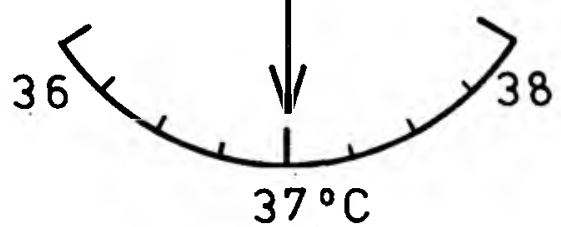

Fig. 1. Heat Balance
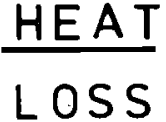


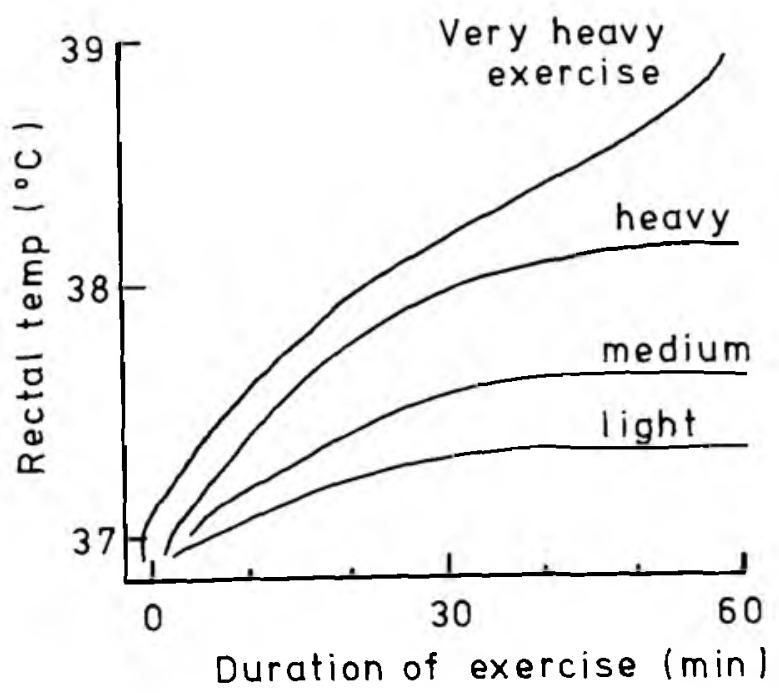

Fig. 2. Body Temperature at Different Work Loads

Shivering alone can increase heat production 3 to 5 fold whilst vigorous exercise may increase metabolic rate by 20 25 times the basal level. This rate of production can theoretically increase the body temperature by $1^{\circ} \mathrm{C}$ every 5 minutes!

Very heavy exercise is sufficient to maintain an adequate body temperature at ambient temperatures of $-30^{\circ} \mathrm{C}$ without the need for heavy clothing.

\section{Regulation of body temperature}

This is done by specialized neurones at the base of the brain in the hypothalamus which act as a "thermostat". A re- setting of this regulator is responsible for the high temperature associated with infections.

\section{Factors affecting heat tolerance}

Age: Studies of heat tolerance in subjects as old as 85 years have failed to show any fall off in tolerance with age.

Sex: It is well known that women start sweating at a higher skin and core temperature and produce smaller volumes, yet their heat tolerance is similar to that of males. They probably rely more on circulatory adjustments and have the advantage of less fluid loss and hence better hydration.

Obesity: Fat people have a definite reduction in heat tolerance as it has been shown that they have a $31 / 2$ times increased incidence of fatal heat stroke compared to lean individuals. This poor heat tolerance is due to the insulating properties of fat coupled with a lower body surface area to weight ratio.

\section{Acclimatization}

Acclimatization in a hot environment is maximal during the first week and complete by about 10 days. Features are: (a) an increased sweating capacity; (b) production of more dilute sweat; (c) less tachycardia with heat; (d) a more even distribution of sweat over the whole body.

\section{Training}

Fitness promotes heat tolerance by two mechanisms: (a) sweating begins at a lower body temperature; (b) for the same workload a fit person will have a lower body temperature.

\section{Presence of a pyrexial illness}

This is an extremely important issue. A person who has a mild cold or "flu" and is slightly feverish has had a "readjustment" of the hypothalamic temperature regulating mechanism and is much more likely to develop hyperpyrexia
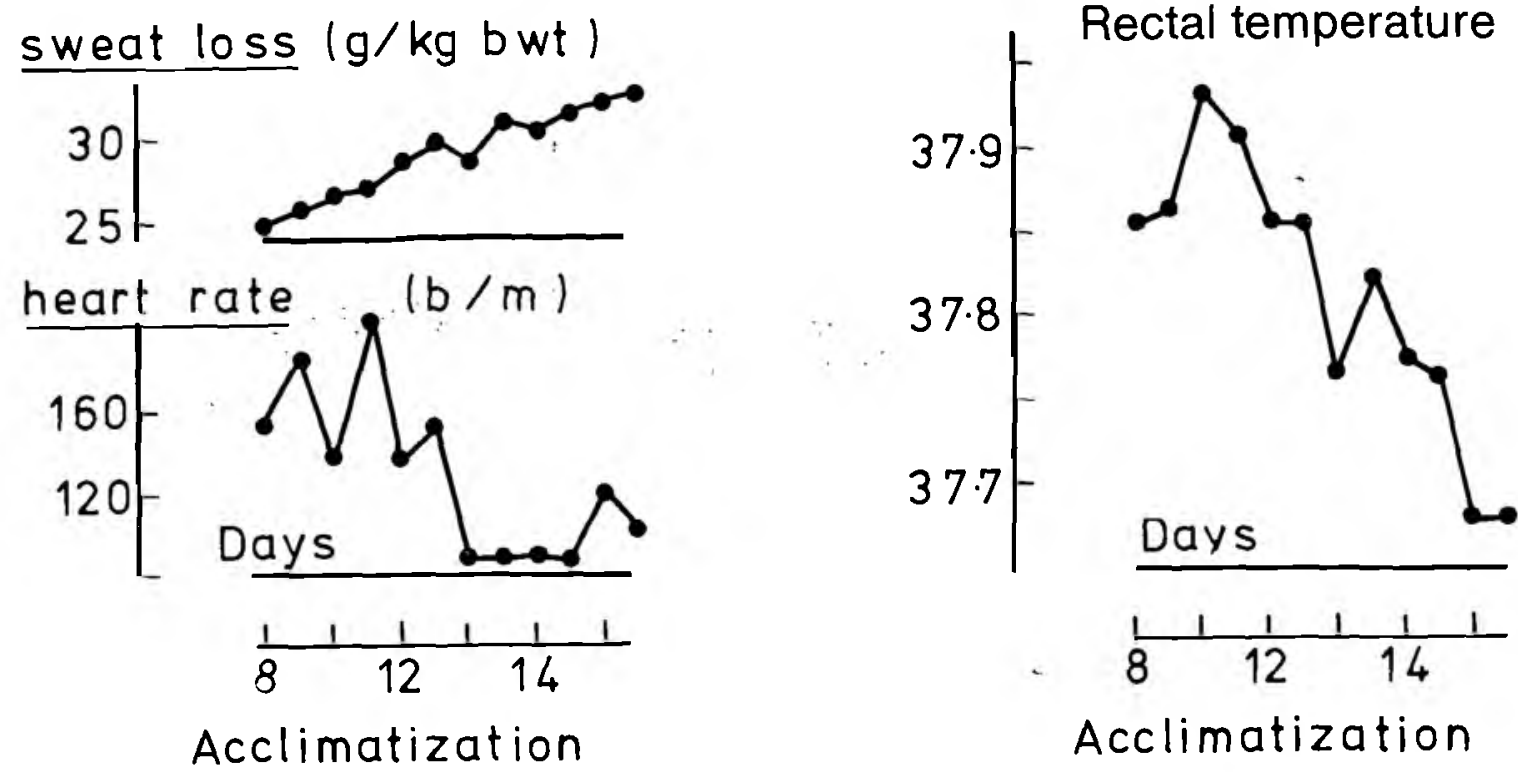

Fig. 3. Development, of Heat Acclimatization

During acclimatization heart rate changed most rapidly, then sweat rate and finally rectal temperature. 

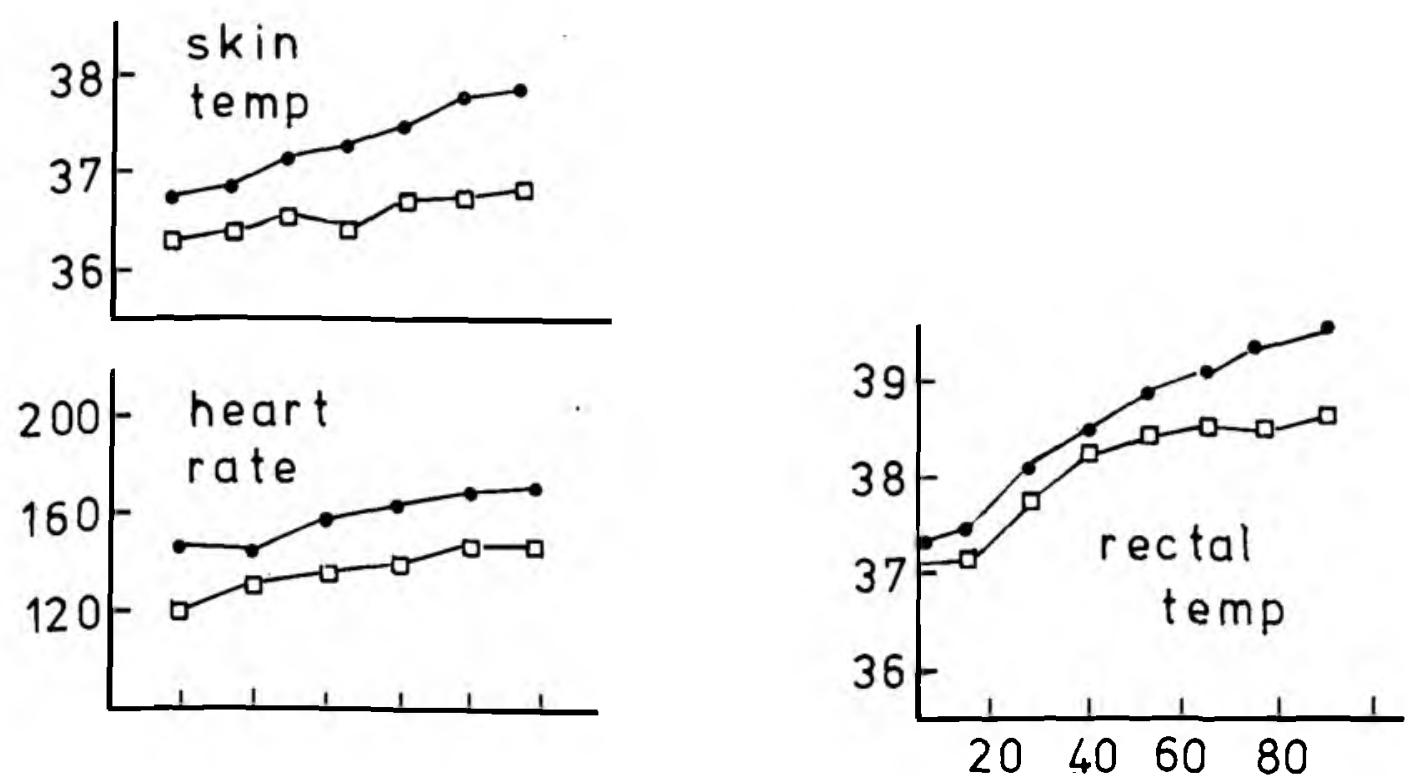

\section{EXERCISE TIME (minutes)}

- Untrained subjects $\square$ Trained subjects

Fig. 4. Relationship between Training and Heat Tolerance

and heat stroke than a "normal" person. These persons are at extreme risk when exercising in a hot environment.

\section{State of hydration}

Dehydration even of a moderate degree (equivalent to a $1 \%$ drop in body weight) is associated with a significant increase in body temperature compared to the same exercise with normal hydration. When water loss reaches 4 to $5 \%$ of body weight, a definite impairment in physical work capacity and physiologic function is noted.

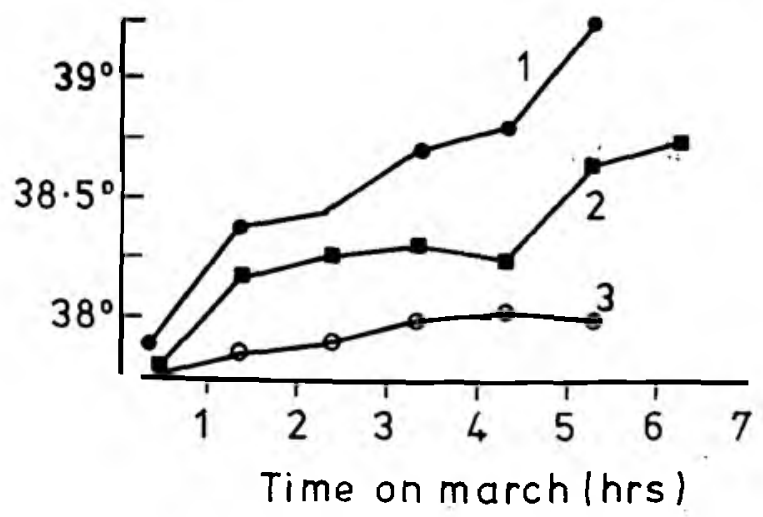

Fig. 5. Relationship between Water Intake and Heat Tolerance

1. Water loss not replaced. 2. Water drank ad lib

3. Water loss replaced hourly

\section{Heat exhaustion}

This term encompasses a wide range of heat related disorders ranging from "fainting" whilst standing for a long period in the heat, to severe dehydration and circulatory collapse. Certain features, however, are common to these disorders:- (1) The body temperature is normal or only slightly raised; (2) The cardinal feature is hypotension due either to maldistribution of cardiac output to skin and muscles and pooling of blood in the legs resulting in a drop in blood pressure and tachycardia or associated with various degrees of salt and water deficit due to prolonged sweating without adequate replacement.

Clinically the patient presents with headaches, dizziness, general weakness, a rapid pulse, reduced but not absent sweating and a body temperature not dangerously high.

Treatment includes stopping of exercise, moving the person to a cool environment, and the administration of fluids.

\section{Heat stroke}

During World War 11 it is estimated that about 200 recruits died from heat stroke in training centres in the U.S.A. This figure probably underestimates the problem as for every person who dies, there are many others who are severely incapacitated but eventually recover.

With the increasing popularity of running as a recreational activity, the correct assessment of a patient suffering from heat stress is vitally important as cases of heat stroke will die rapidly if incorrectly handled.

\section{HEAT STROKE IS A MEDICAL EMERGENCY}

Heat stroke results from failure of the temperature regulating mechanisms of the body brought on by 
excessively high temperatures. Once this stage is reached, sweating becomes ineffective, the body temperature rises rapidly and uncontrollably to levels in excess of $42^{\circ} \mathrm{C}$, soon the patient becomes confused, loses consciousness, suffers circulatory collapse and dies.

Premonitory signs include incoherent speech, disorientation, an altered gait and staggering.

Anhydrosis, i.e. absence of sweating, is classically described, BUT THIS MUST NOT BE RELIED ON TO DISTINGUISH HEAT STROKE FROM THE LESS SERIOUS HEAT INJURY, HEAT EXHAUSTION, as mild sweating may be present.

The blood pressure is moderately to severely reduced with a tachycardia (pulse $120-140 / \mathrm{min}$ ) but it may be slower in highly trained athletes.

\section{Treatment}

The body temperature must be lowered to below $40^{\circ} \mathrm{C}$ as soon as possible. Massage with wet towels packed with ice is very effective. Once below $40^{\circ} \mathrm{C}$ cooling may be more passive. Fluid therapy should include glucose and electrolyte solutions, but excessive administration should be avoided to prevent circulatory overload and cerebral oedema. Serum levels of glucose and electrolytes must be measured early and thereafter patient closely monitored in hospital for at least 36 hours.

\section{Marathon running}

During steady state exercise at $75 \%$ of maximum physical work capacity, heat production may reach $1200 \mathrm{~K} / \mathrm{cal} / \mathrm{hr}$ and corresponding rectal temperatures of $39-41^{\circ} \mathrm{C}$. These temperatures apparently cause no harm. The critical maximum temperature appears to be in the vicinity of $42^{\circ} \mathrm{C}$

Most cases of heat stroke occur in novice, overweight, undertrained runners taking in too little fluid in long runs such as marathons.

It is, however, vital to realize that heat stroke may also occur in well trained athletes running relatively short distances such as $5 \mathrm{~km}$ when dehydration and fluid replenishment play a minimal role. In fact, it is the elite runner running at nearly maximum energy expenditure who is at greatest risk as his rate of heat production is so high. Heat stroke may occur within minutes as has been reported in runners who, near the end of a marathon (which generally tends to be mid-morning when the ambient temperature has started rising), suddenly start speeding up for a fast finish and exceed the capacity of their bodies to cope with the extra heat produced.

\section{Prevention}

Guidelines for conducting exercise in hot weather such as maximum temperatures and humidity permissible, have been established and must be firmly adhered to.

As important should be the awareness by all persons of all the factors involved in exercise in a warm environment and the prevention, diagnosis and management of heat injury. 